\title{
Tribological testing of sliders on discrete track media and verification with numerical predictions
}

\author{
Maik Duwensee $\cdot$ D. E. Lee $\cdot$ Y. Yoon $\cdot$ F. E. Talke $\cdot$ \\ S. Suzuki $\cdot$ J. Lin
}

Received: 19 July 2007/ Accepted: 29 January 2009/Published online: 4 April 2009

(c) The Author(s) 2009. This article is published with open access at Springerlink.com

\begin{abstract}
Flyability" tests were conducted with sliders designed for discrete track recording disks. Laser Doppler vibrometry and acoustic emission were used to characterize the dynamics of the sliders as a function of discrete track parameters. Lubricant depletion was observed depending on the slider nominal flying height. Comparison of experimental results with numerical predictions showed good qualitative agreement.
\end{abstract}

\section{Introduction}

In discrete track recording, magnetic bits are stored on discrete circumferential tracks. In bit patterned media, bits are recorded on single "island-like" regions on the disk surface. In the case of bit patterned media, magnetic transition noise is eliminated. In the case of discrete track recording, magnetic transition noise is eliminated only in the radial direction (Soeno and Moriya 2003). Soeno et al. (2005) and Wachenschwanz et al. (2005) reported an increase in the signal to noise ratio (SNR) and a better write efficiency for discrete track recording. Patterned media head/disk interfaces are challenging from a tribology point of view (Suzuki et al. 2007), since discrete tracks or bits influence the head/disk interface dynamics and thereby the

M. Duwensee $(\bowtie) \cdot$ D. E. Lee · Y. Yoon · F. E. Talke University of California, San Diego, 9500 Gilman Dr., La Jolla, CA 92093, USA

e-mail: maik.work@gmail.com

S. Suzuki · J. Lin

Western Digital, Incorporated, 1710 Automation Parkway,

San Jose, CA 95131, USA interface reliability. Very high and localized air bearing pressure peaks are predicted from numerical simulations of discrete track head/disk interfaces (Duwensee et al. 2006a). Increased air bearing pressure is likely to cause lubricant depletion.

Duwensee et al. (2006a, b) used a finite-element-based air bearing simulator (Wahl et al. 1996) to study discrete track head/disk interfaces. They simulated the steady state slider flying height and attitude of a typical slider as a function of groove width, groove depth, and track pitch. Different sub-ambient pressure slider bearing designs were used. An empirical equation was found to predict the loss of flying height of a slider for a discrete track head/disk interface compared to its flying height on a "smooth" disk.

In this study, an experimental investigation was conducted to investigate the flying characteristics of typical air bearing sliders designed for discrete track media using laser Doppler vibrometry and acoustic emission. Long term "flyability" tests were also performed in order to determine lubricant loss in the "wear track" of the slider.

\section{Numerical model and results}

Figure 1 shows numerical results for the loss of flying height of typical magnetic sliders as a function of groove depth $d$ (Duwensee et al. 2006a, b). We observe that the flying height loss increases linearly with groove depth, independent of slider design. The loss in flying height $\Delta \mathrm{FH}$ follows the empirical equation:

$\Delta \mathrm{FH}=d \cdot \frac{w}{p}$,

where $d$ is the groove depth, $w$ the groove width, and $p$ is the track pitch. 


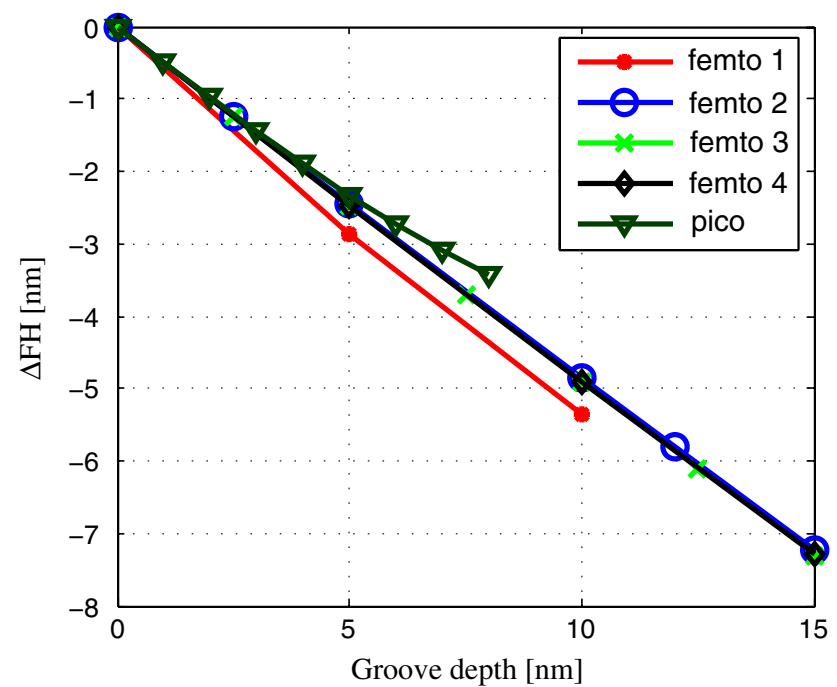

Fig. 1 Flying height loss $\Delta \mathrm{FH}$ as a function of groove depth and slider design $(w / p=0.5)$ (Duwensee et al. 2006b)

Numerical simulations of the air bearing pressure distribution (Fig. 2) show that high pressure peaks can be expected for the land regions of a discrete track recording head/disk interface. High pressure peaks are likely to cause lubricant depletion, which could lead to failure of the head/ disk interface.

In order to study the tribological characteristics of discrete track head/disk interfaces, it would be ideal to have a large matrix of disks with different discrete tracks available for experimental testing. At present, however, discrete track disks are difficult to manufacture and the experimental verification of Eq. 1 is limited to a small number of isolated test samples. To verify numerical predictions with a limited number of test samples, we have chosen the following approach. We have first investigated the flying and contact characteristics of typical "present-day" sliders on "smooth" disks using laser Doppler vibrometry and acoustic emission analysis. We have then tested the same sliders on discrete track disks with increasing groove depth, and have analyzed the laser Doppler vibrometer and acoustic emission signals for each slider/disk combination. Using the empirical flying height loss equation (Eq. 1), we have predicted the flying height loss for each slider/disk combination. If the prediction shows a flying height loss resulting in "zero" or "negative" flying height, it is apparent that laser Doppler vibrometry and acoustic emission signals should indicate contact between slider and disk. Thus, by comparing the numerical predictions for the flying height loss of different slider/disk combinations with laser Doppler vibrometer and acoustic emission measurements, an indirect verification of the numerical predictions can be achieved.

\section{Experimental setup and parameters}

Figure 3 shows a schematic of the experimental setup used in this investigation. The setup consists of an air bearing spindle, a slider attached to a suspension, a laser Doppler vibrometer (LDV), and acoustic emission (AE) sensor equipment. The laser Doppler vibrometer and acoustic emission signal lines are connected to a PC based data acquisition system. "MATLAB ${ }^{\odot}$ " was used for data analysis. The disk was loaded onto the spin-stand, and the slider was placed on the disk. For the investigations reported in this paper the slider was positioned at a radial position of $37.5 \mathrm{~mm}\left(1.5^{\prime \prime}\right)$ from the disk center. The skew angle was chosen to be zero. A rotational speed of 5,400 rotations per minute (rpm) was used, resulting in a velocity of $22 \mathrm{~m} / \mathrm{s}$.

Two pico form factor slider designs (slider I and slider II) were used in this investigation. Figure 4 shows the air bearing contours for both slider designs, obtained from optical surface profilometer measurements. The different edge height levels are indicated in Fig. 4. As can be seen, both air bearing surfaces are similar. However, the air bearing surface features of slider I have different height levels compared to the air bearing features of slider II. For instance, the large cavity in the center of slider I has a height level of approximately $2.39 \mu \mathrm{m}$, while the center cavity of slider II has a height level of approximately $1.95 \mu \mathrm{m}$. The nominal flying height of slider I on a smooth disk surface is $11 \mathrm{~nm}$ at a velocity of $22 \mathrm{~m} / \mathrm{s}$. The nominal flying height of slider II on a smooth disk surface is $20 \mathrm{~nm}$ at a velocity of $22 \mathrm{~m} / \mathrm{s}$.

Five different types of disk were used for the investigations reported in this paper. The specifications for the
Fig. 2 Typical pressure distribution at the trailing edge center for a smooth disk, b $15 \mathrm{~nm}$ groove depth, c $75 \mathrm{~nm}$ groove depth
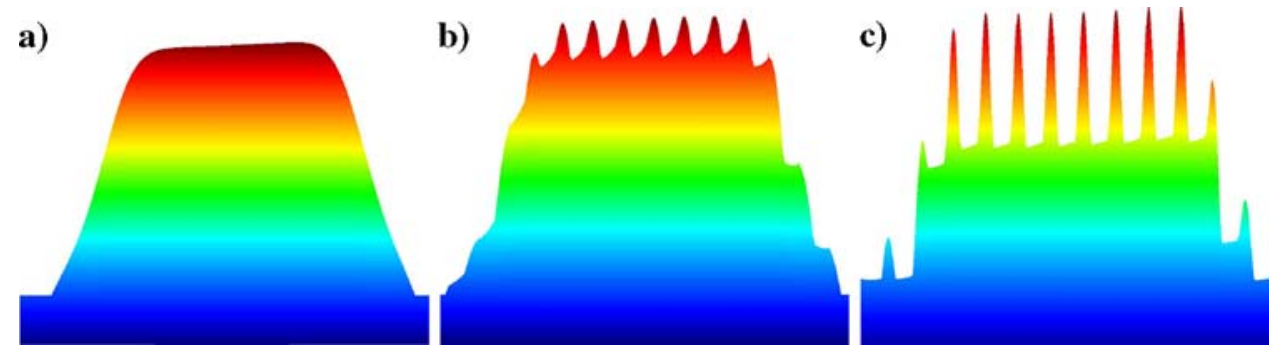


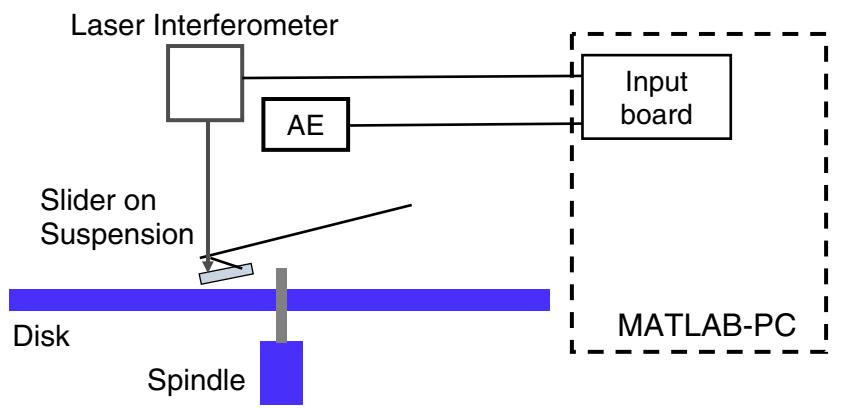

Table 2 Predicted flying height loss and predicted flying heights

\begin{tabular}{llll}
\hline & $\Delta \mathrm{FH}(\mathrm{nm})$ & $\mathrm{FH}_{\text {slider I }}(\mathrm{nm})$ & $\mathrm{FH}_{\text {slider II }}(\mathrm{nm})$ \\
\hline $\mathrm{A}$ & 0 & 11 & 20 \\
$\mathrm{~B}$ & 1.3 & 9.7 & 18.7 \\
$\mathrm{C}$ & 8.8 & 2.2 & 11.2 \\
$\mathrm{D}$ & 11.7 & -0.7 & 8.3 \\
$\mathrm{~F}$ & 35 & -24 & -15 \\
\hline
\end{tabular}

Fig. 3 Schematic of experimental setup

Fig. 4 Air bearing surface of a slider I and b slider II
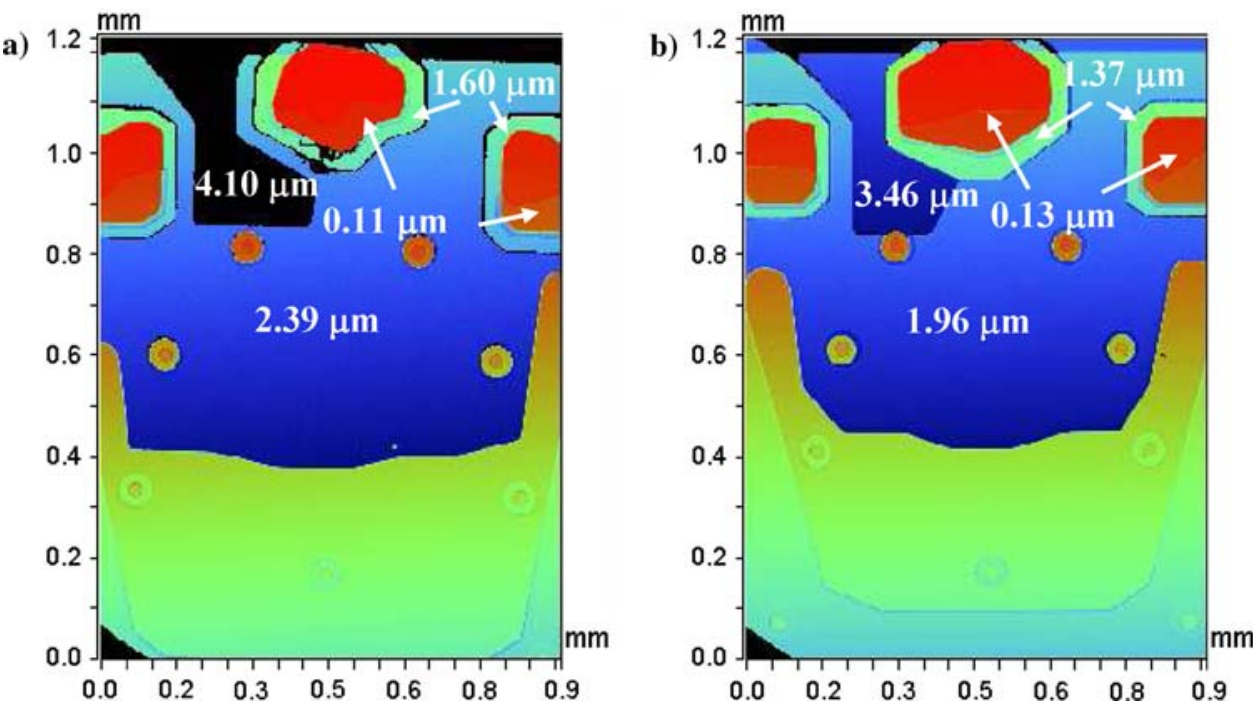

disks used are summarized in Table 1. The predicted flying height loss $\Delta \mathrm{FH}$ for each slider/disk combination is shown in Table 2 together with the predicted flying height.

We observe that slider I is predicted to fly at a flying height of $2.2 \mathrm{~nm}$ on disk $\mathrm{C}$, while the flying height of slider II on the same disk is $11.2 \mathrm{~nm}$. In addition, the flying height of slider I on disk D is predicted to be $-0.7 \mathrm{~nm}$, while the flying height of slider II on disk D is $8.3 \mathrm{~nm}$. Finally, the flying height of slider I and II on disk F is predicted to be -24 and $-15 \mathrm{~nm}$, respectively. From the prediction of the flying height of Table 2, it is apparent that

Table 1 Specifications of disks

\begin{tabular}{lcccl}
\hline & $\begin{array}{l}\text { groove depth } \\
d(\mathrm{~nm})\end{array}$ & $\begin{array}{l}\text { track pitch } \\
p(\mathrm{~nm})\end{array}$ & $\begin{array}{l}\text { groove width } \\
w(\mathrm{~nm})\end{array}$ & $w / p$ \\
\hline $\mathrm{A}$ & 0 & 0 & 0 & 0 \\
$\mathrm{~B}$ & 5 & 380 & 100 & 0.26 \\
$\mathrm{C}$ & 20 & 225 & 100 & 0.44 \\
$\mathrm{D}$ & 30 & 380 & 148 & 0.39 \\
$\mathrm{~F}$ & 70 & 380 & 190 & 0.50 \\
\hline
\end{tabular}

slider I should show contacts on disk D and F, and likely also on disk C. Slider II, on the other hand, should show contacts only on disk F.

\section{Experimental results and discussion}

Figure 5 shows the slider displacement spectrum of sliders I and II flying on disk A (smooth disk). We observe that the spectra for both sliders are similar, the main difference being increased magnitudes at frequencies of 140 and $210 \mathrm{kHz}$, respectively, for slider II. These frequencies are related to the first and second pitch resonance frequency. Since the flying height of slider II on a smooth disk is much larger than that of slider I, the increased pitch amplitudes can be expected.

Figure 6 shows the slider displacement spectrum for sliders I and II flying on disk C (groove depth $d=20 \mathrm{~nm}$; ratio of groove width to track pitch $w / p=0.44)$. We observe well defined peaks at $130 \mathrm{kHz}$ (first pitch resonance frequency) for slider II and near $180 \mathrm{kHz}$ for slider I (second pitch resonance frequency). 


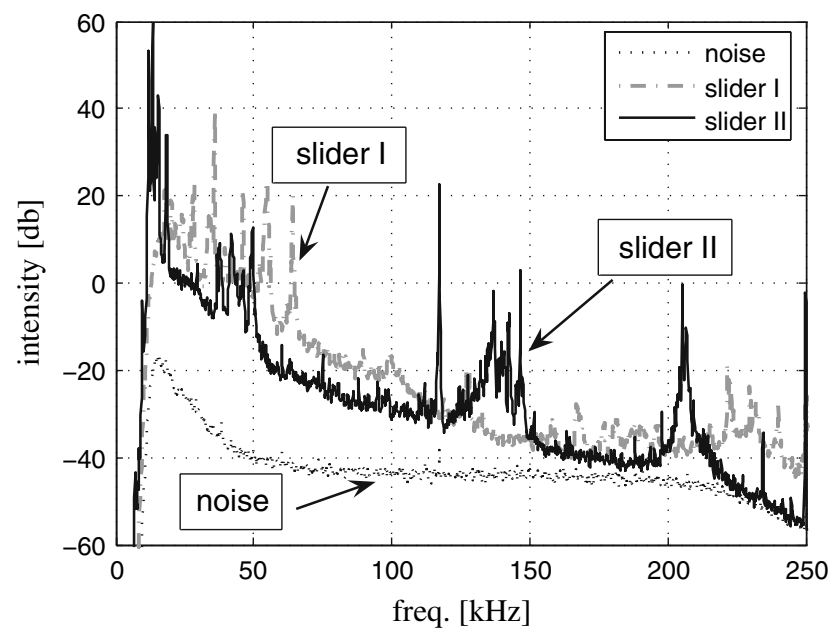

Fig. 5 Displacement spectra for sliders I and II for disk A (smooth disk)

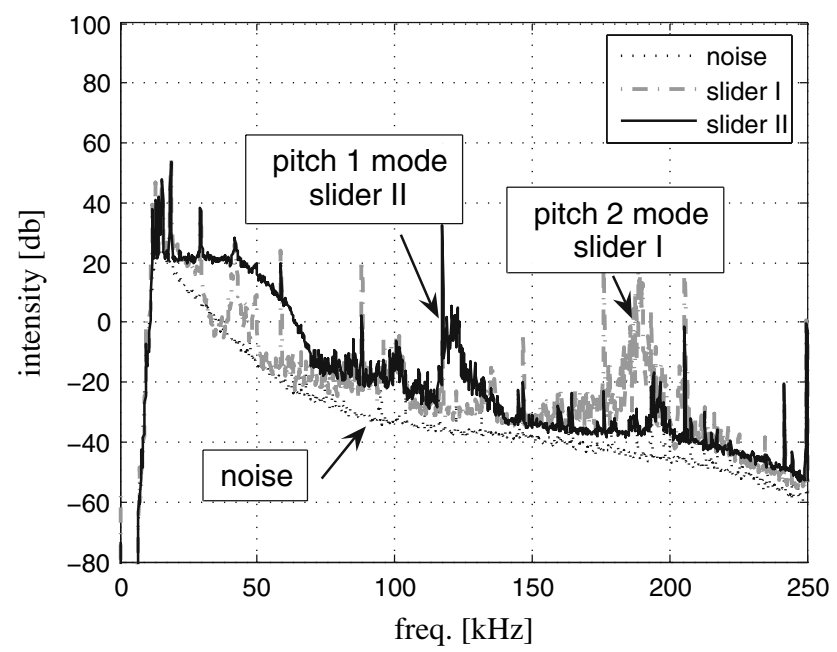

Fig. 6 Displacement spectra for sliders I and II for disk C (groove depth $d=20 \mathrm{~nm}$

Figure 7 shows the slider displacement spectrum for sliders I and II flying on disk D (groove depth $d=30 \mathrm{~nm}$; ratio of groove width to track pitch $w / p=0.39$ ). We note that the spectrum for slider II is similar to that shown in Fig. 6. Again, a strong peak is observed at $130 \mathrm{kHz}$. A completely different spectrum is observed, however, for slider I. In particular, a large number of discrete frequencies is present over the complete frequency range for slider I. The presence of these frequencies for slider I indicates that contacts are present, i.e., slider I is not flying on disk D. Acoustic emission measurements support this finding.

After completion of the tests on disk D, sliders I and II were flown on disk $\mathrm{F}$ (groove depth $d=70 \mathrm{~nm}$; ratio of groove width to track pitch $w / p=0.5$ ). Based on Eq. 1, the nominal flying height loss for slider I on disk F is $35 \mathrm{~nm}$,

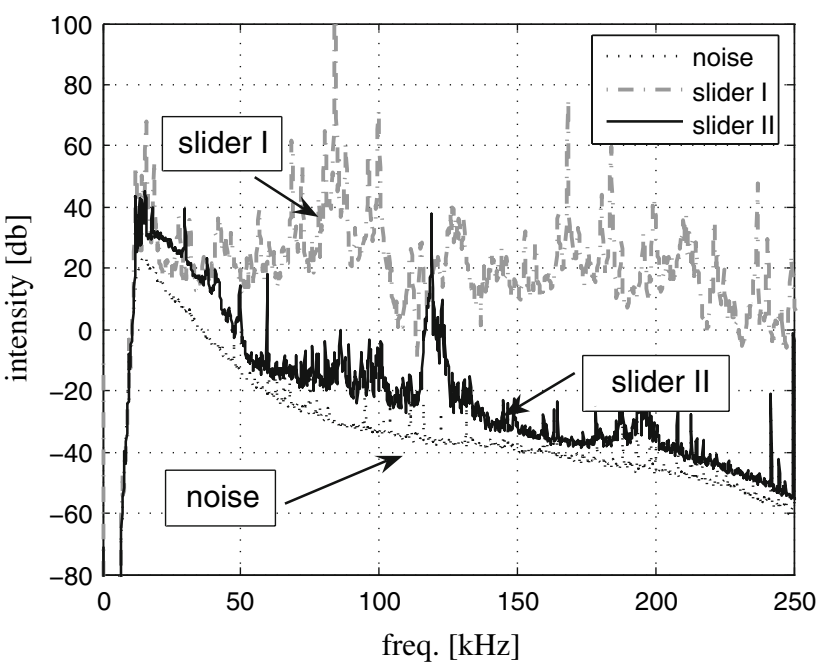

Fig. 7 Displacement spectra for sliders I and II for disk D (groove depth $d=30 \mathrm{~nm}$ )

i.e, the flying height loss on disk $\mathrm{F}$ is larger then the nominal flying height of either slider on a "smooth" disk. Thus, contact is predicted for both sliders on disk F. Constant speed "drag" testing on disk F confirmed the above prediction, i.e., a wear track was formed on the disk immediately after the start of the experiments.

To characterize the dynamic behavior of sliders I and II for all media investigated the standard deviation of the flying height modulation during one revolution was determined and plotted in Fig. 8. The predicted flying heights for slider I and II based on Eq. 1 are also indicated in the figure. We observe that the flying height modulation is nearly the same for sliders I and II on disks A, B, and C. A substantial increase in flying height modulation is observed for slider I on disk D and an even larger increase on disk F. We also note that the flying height modulation for slider II on disk $\mathrm{D}$ is the same as on disk $\mathrm{C}$, but that a large increase occurs for disk F. The low values of the standard deviation of flying height modulation for slider I on disks A, B, and C and for slider II on disks A, B, C, and D indicate that the slider is flying. This result is in agreement with the predicted flying heights for both sliders on disks A through F. The predicted flying height for slider I is "negative" for disk $\mathrm{D}(-0.7 \mathrm{~nm})$ and disk $\mathrm{F}(-24 \mathrm{~nm})$. Thus, contacts are predicted by Eq. 1 for these slider/disk combinations. The flying height modulation results shown in Fig. 8 agree with these predictions. For slider II, the predicted flying height for disk $\mathrm{F}$ is $-15 \mathrm{~nm}$, i.e., contact is predicted. The results of Fig. 8 for slider II on disk F are in agreement with these predictions.

To investigate the long term tribological characteristics of the head/disk interface with discrete track media, extended "flyability" tests were performed. Slider II was flown on disk C (groove depth $d=20 \mathrm{~nm}$; ratio of groove 


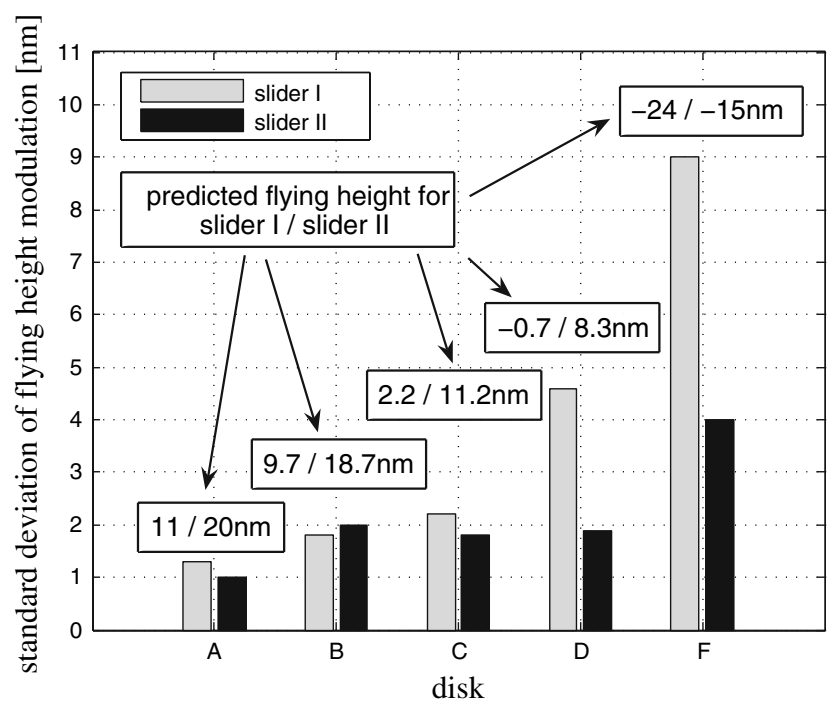

Fig. 8 Standard deviation of slider flying height modulation for sliders I and II on disks A through F

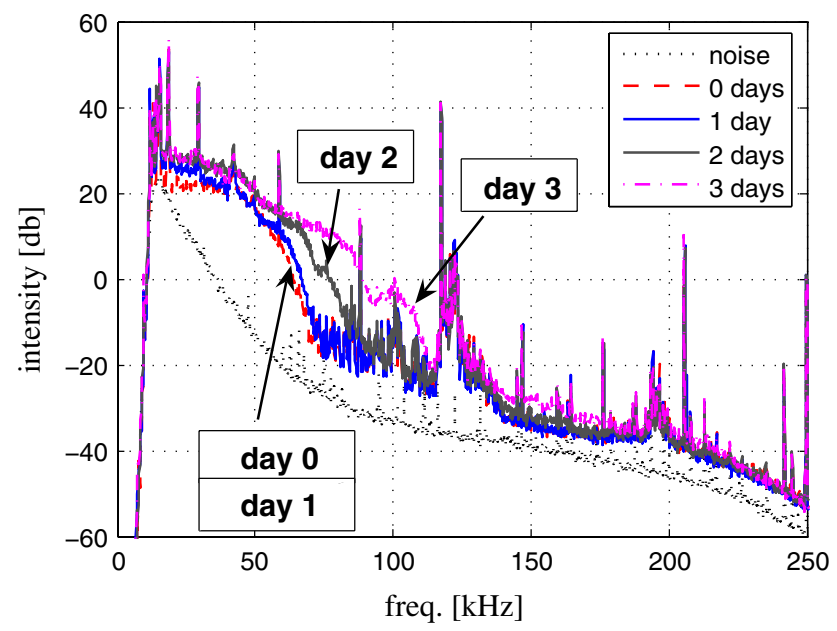

Fig. 9 Displacement spectra for long-time flying of slider II on disk $\mathrm{C}$ (groove depth $d=20 \mathrm{~nm}$ )

width to track pitch $w / p=0.44$ ), and disk D (groove depth $d=30 \mathrm{~nm}$; ratio of groove width to track pitch $w /$ $p=0.39$ ) on a single track. The slider displacement (laser Doppler vibrometer) and acoustic emission were recorded at 1 day intervals.

Figure 9 shows the slider displacement spectra of slider II taken over several days of continuous single-track flying on disk C (groove depth $d=20 \mathrm{~nm}$; ratio of groove width to track pitch $w / p=0.44)$. The displacement spectra between day 0 and day 1 do not show any change. After 2

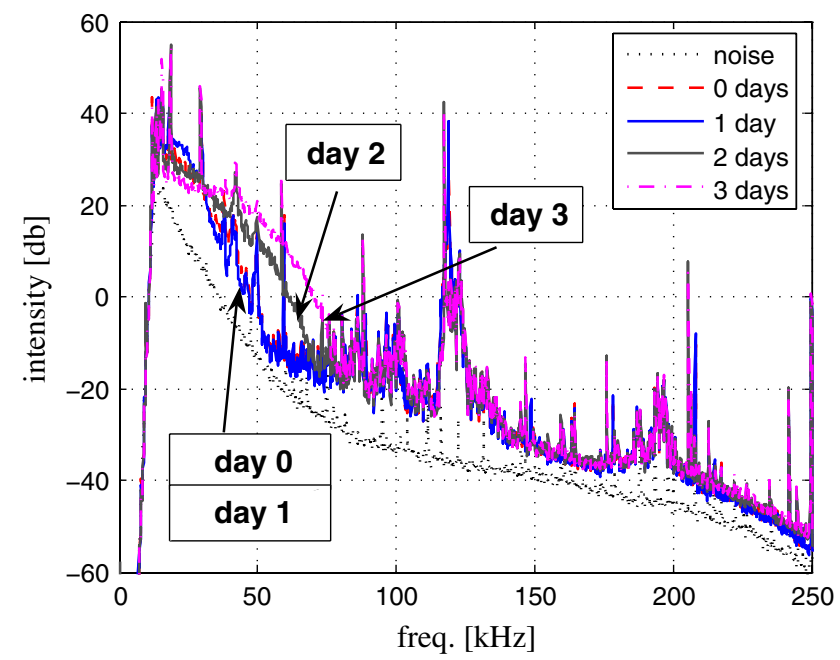

Fig. 10 Displacement spectra for long-time flying of slider II on disk $\mathrm{D}$ (groove depth $d=30 \mathrm{~nm}$ )

days, additional frequencies in the $50-75 \mathrm{kHz}$ range are observed. This trend continues for day three, with the appearance of additional frequencies in the $25 \mathrm{kHz}$ to $100 \mathrm{kHz}$ range. A similar trend is observed in the slider displacement spectra for slider II on disk D (groove depth $d=30 \mathrm{~nm}$; ratio of groove width to track pitch $w / p=0.39)$, shown in Fig. 10 .

It is justifiable to postulate that continuous flying on a single track causes lubricant depletion, resulting in increased slider dynamics.

Lubricant displacement measurements were conducted using surface reflectance analysis (Deoras et al. 2003). Figure 11 shows measurements taken at the beginning of the experiment ( 0 days), and after 3 days of single-track continuous flying on disk $\mathrm{C}$ (groove depth $d=20 \mathrm{~nm}$; ratio of groove width to track pitch $w / p=0.44$ ). The lefthand pictures in Fig. 11 show the reflectance map of the discrete track surface. The right-hand plots show a radial trace of the reflectance. Lubricant loss in the "wear" track of the slider is observed. Figure 12 shows measurements taken for three days of single-track continuous flying of slider II on disk D (groove depth $d=30 \mathrm{~nm}$; ratio of groove width). Clearly, lubricant loss in the "wear" track of the slider is present.

Figure 13 shows the standard deviation of the flying height modulation as a function of time for slider II flying over disk C and D. An increase in the standard deviation of the flying height modulation is observed as a function of time, indicating increased slider dynamics. We postulate that the increase in slider dynamics is related to lubricant depletion. 
Fig. 11 Surface reflectance analyzer (SRA) data for longtime flying of slider II on disk C (groove depth $d=20 \mathrm{~nm}$ )

Fig. 12 Surface reflectance analyzer (SRA) data for longtime flying of slider II on disk D (groove depth $d=30 \mathrm{~nm}$ )
0 days
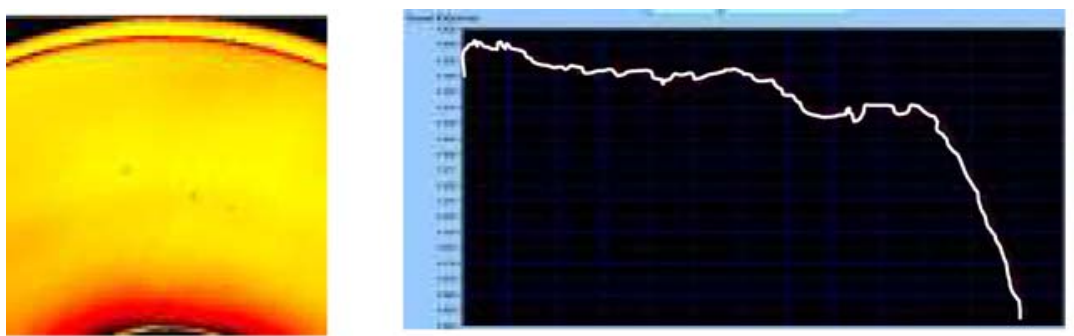

3 days

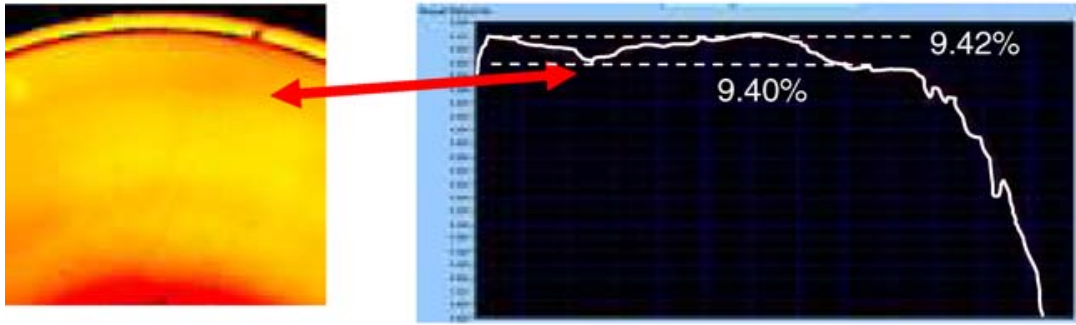

0 days
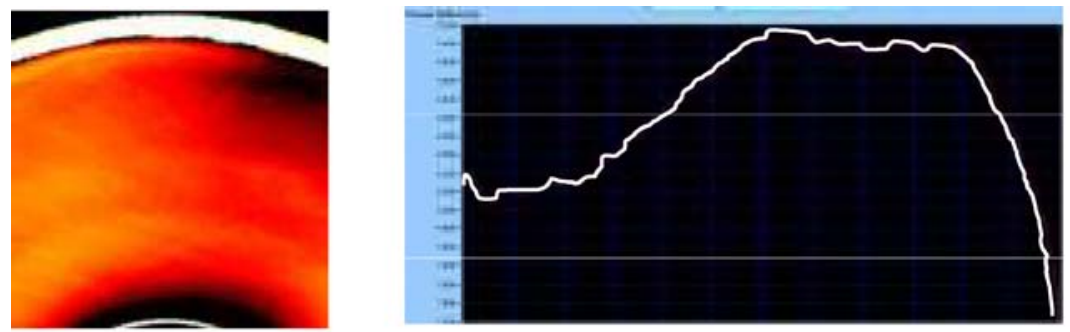

3 days

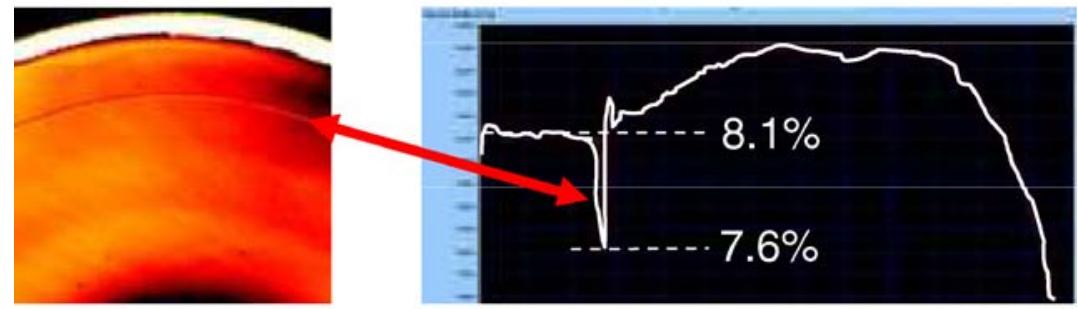

\section{Summary and conclusions}

To validate numerical flying height predictions for discrete track head/disk interfaces, the "flyability" of two types of sliders on a limited number of discrete track disks with different discrete track parameters was investigated. Equation 1 was used to predict the occurrence of contact for the discrete track head/disk combinations used in the experiments. Contact is expected whenever the predicted flying height is smaller than zero. Contact was observed using laser Doppler vibrometry and acoustic emission measurements. Good qualitative agreement between the numerical flying height prediction and the experiments was found. However, only a small number of experiments could be conducted due to the limited number of samples (disks and sliders) available. Additional experiments need to be performed with a large number of samples to validate the numerical predictions in a statistical sense.

Long-term "flyability" tests have shown the appearance of additional frequencies in the slider displacement spectra (Figs. 9, 10) as a function of time. We hypothesize that the appearance of the additional frequencies is related to increased slider/disk interactions due to lubricant depletion.

The flyability and longterm tribological tests performed in this investigation indicate that numerical predictions of flying height loss are an important tool in predicting the performance of discrete track head/disk interfaces. 


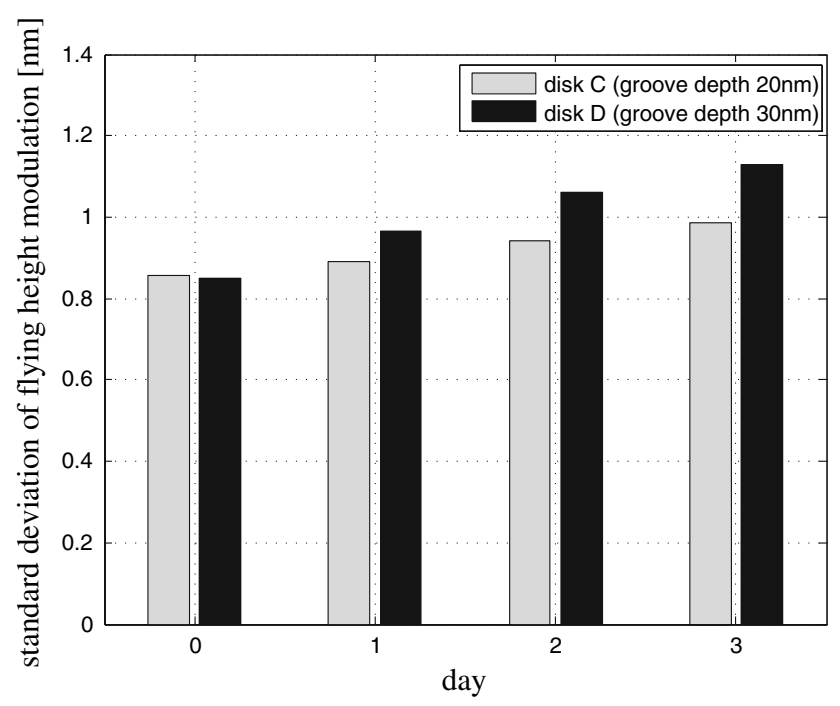

Fig. 13 Standard deviation of slider flying height modulation as a function of time for slider II flying over disk C and D

Acknowledgments This work was partially supported by a grant from the Information Storage Industry Consortium (INSIC). The authors would like to thank Dr. David Wachenschwanz (KOMAG Inc.) and Dr. J. P. Peng (Western Digital Tech.) for their interest and help with securing experimental components.

Open Access This article is distributed under the terms of the Creative Commons Attribution Noncommercial License which permits any noncommercial use, distribution, and reproduction in any medium, provided the original author(s) and source are credited.

\section{References}

Deoras S, Chun S, Vurens G, Talke F (2003) Spreading and mobility analysis of PFPE lubricants using surface reflectance analyzer. Trib Int 36(4-6):241-246

Duwensee M, Suzuki S, Lin J, Wachenschwanz D, Talke F (2006a) Air bearing simulation of discrete track recording media. IEEE Trans Magn 42(10):2489-2491

Duwensee M, Suzuki S, Lin J, Wachenschwanz D, Talke F (2006b) Simulation of the head disk interface for discrete track media. Microsyst Technol (Published Online)

Soeno Y, Moriya M, Kaizu A, Takai M (2005) Performance evaluation of discrete track perpendicular media for high recording density. IEEE Trans Magn 41(10):3220-3222

Soeno Y, Moriya M et al (2003) Feasibility of discrete track perpendicular media for high track density recording. IEEE Trans Magn 39(1):1967-1971

Suzuki S, Dorsey P, Nishihira H, Lin J, Wachenschwanz D, Duwensee M, Talke F (2007) Discrete track recording media and its tribological challenges in head/disk interface. J Japn Soc Trib 52(6)

Wachenschwanz D, Jiang W, Roddick E et al (2005) Design of a manufacturable discrete track recording medium. IEEE Trans Magn 41(2):670-675

Wahl M, Lee P, Talke F (1996) An efficient finite element-based air bearing simulator for pivoted slider bearings using bi-conjugate gradient algorithms. STLE Trib Trans 39(1) 